\title{
ЭСТЕТИКА ВОСПРОИЗВОДИМОГО В СОВРЕМЕННОМ ИСКУССТВЕ
}

\begin{abstract}
Аннотация. В статье рассматривается искусство в эпоху его технического производства и обосновывается необходимость выделения воспроизводимых искусств в отдельную категорию. Стремление автора переосмыслить некоторые тендениии развития в области современного искусства обусловило рассмотрение и дифберенииацию следующих понятий: оригинал, копия, репродукиия, подлинность, множественность и воспроизводимость произведения искусства. В статье доказывается тезис о том, что у произведений воспроизводимых искусств отсутствует оригинал в строгом понимании этого слова. Кроме того, разрабатывается концепиия эксплицитных версий, вдохновленная идеями канадского профессора философии Д. Лопеса. Новое понятие «эксплииитная версия» сопоставляется с привычными понятиями «копия» и «оригинал» произведений. Кроме того, на основе анализа самых разных примеров творческих работ автор выделяет интерактивное искусство в особый вид воспроизводимых искусств, доказывая, что результатом взаимодействия аудитории с интерактивным произведением является не новая творческая работа, а эксплицитная версия. Ключевые слова: копирование произведений искусства, множественное искусство, воспроизводимое искусство, интерактивное искусство, компьютерное искусство, современное искусство, оригинал произведения, копия произведения, эксплииитная версия, подлинность.
\end{abstract}

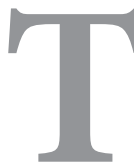
ехнический прогресс позволил произведениям искусства быть размноженными и растиражированными в бесчисленных количествах. Произведение искусства в эпоху технического воспроизведения является актуальным предметом философских и искусствоведческих исследований. Одним из первых ученых, обративших внимание на проблему искусства в эпоху его технической воспроизводимости был Вальтер Беньямин. Развитие критической теории и подходов к интерпретации современного искусства во многом было предопределено поставленными В. Беньямином вопросами о природе произведения искусства в контексте технологий индустриального производства. В. Беньямин утверждал, что возможность репродукции лишает произведение искусства его ценности. Само Искусство как бы покидает его: «То, что при этом исчезает, может быть суммировано с помощью понятия ауры: в эпоху технической воспроизводимости произведение искусства лишается своей ауры, становится массовым» ${ }^{1}$. Благодаря техническому прогрессу у произведения искусства появляется способность быть размноженным, т.е.

\footnotetext{
${ }^{1}$ Беньямин В. Произведение искусства в эпоху его технической воспроизводимости. Избранные эссе. М.: Медиум, 1966. С. 70.
}

растиражированным в бесчисленных количествах. Искусство становится максимально приближенным к массовой аудитории, а функционирование копий и репродукций в обществе делает существование оригиналов менее значимым.

Процесс омассовления искусства обуславливает рост значения экспозиционной функции. Впрочем, историческое развитие художественной деятельности начинается с произведений, состоявших на службе культа. Для этих произведений, как можно предположить, было важнее, чтобы они имелись в наличии, чем то, чтобы их видели. Эстетическая привлекательность и художественная выразительность предметов искусств выносилась за границы культа. Экспозиционная ценность произведения меркла в тени ритуальной функцией. Первостепенность ритуальной ценности не только оправдывала, но и принуждала скрывать произведение искусства: «некоторые статуи античных божеств находились в святилище и были доступны только жрецу, некоторые изображения богоматери остаются почти весь год занавешенными, некоторые скульптурные изображения средневековых соборов не видны наблюдателю, находящемуся на земле» ${ }^{2}$.

2 Эстетика и теория искусства XX века. Хрестоматия. М.: ACADEMIA XXI: Прогресс-традиция, 2007. С. 251. 
Современные же тенденции развития искусства обуславливают главенство экспозиционной функции. Возможности технического репродуцирования произведения искусств множились и совершенствовались на протяжении тысячелетий. Первоначально воспроизведение предметов искусства было ограничено двумя способами - литьем и штамповкой. Спустя какое-то время мир графики был реформирован изобретением гравюры, а последующее появление книгопечатания изменило весь мир. Вместе с эволюцией процесса технического воспроизведения росла возможность произведений быть открытыми все большему числу зрителей, читателей, слушателей. Доступное широким аудиториям искусство является не только очередным этапом в развитии искусства, но объектом различного рода исследований. Качественные изменения в восприятии воспроизводимого искусства отмечает М. Хайдеггер, который точнее и более развернуто, чем В. Беньямин, раскрывает процесс угасания ауры произведения в связи с ростом выставочной ценности искусства. «Чем больше угасает в искусстве его ритуальный смысл, тем очевидней становится развлекательная его функция, соответствующая в секулярной культуре массовым вкусам и потребностям» ${ }^{1}$.

Новая волна интереса к вопросам, касающихся темы воспроизводимости искусства, была вызвана появлением компьютерных технологий. Файл цифрового изображения может быть копируем бесконечное число раз без потери качества, а копии будут отличаться друг от друга лишь датой. При этом может быть сделано неограниченное количество распечаток каждой копии файла. Аутентичный файл изображения может быть уничтожен в течение короткого времени после его создания, но его копии смогут продолжить свое полноценное существование. Действительно, сегодняшние тенденции развития искусства обуславливают необходимость взглянуть под новым углом на такие смежные понятия, как оригинал, копия, реплика, репродукция, воспроизводимость, множественность и единичность произведений искусства.

Стремительно развивающиеся компьютерные технологии непосредственно влияют на мир искусства, порождая самые разные техно-художественные формы. Чтобы приблизиться к пониманию сущности компьютерного творчества, необходимо глубоко его проанализировать, начав с отвлеченного от компьютерных технологий размышления о произведениях искусства в общем. Прежде всего, надо отметить,

${ }^{1}$ Там же. С. 245. что воспроизводимое (множественное) искусство появилось задолго до появления первого компьютера. Так, например, отпечатки фотографий, оттиски гравюр, распечатки файлов графических редакторов и т.п. создаются не в единственных экземплярах, а в существенно большем, хотя и в некоторых случаях ограниченном, количестве. Данные произведения обладают множественной природой и предполагают неоднократные воспроизведения, что наводит на вопрос о том, как многочисленные экземпляры одного произведения соотносятся друг с другом.

Для начала вспомним, что такое копии произведения. Очевидно, что любое произведение искусства может быть подвергнуто процессу копирования, при этом копирование может осуществляться самыми разными способами: от свободной, приблизительной передачи до выверенного, точного до мельчайших деталей факсимильного воспроизведения. Копии одного и того же произведения могут как явно разниться между собой, так и, наоборот, быть визуально неразличимыми. При этом все копии без исключения восходят к одной изначальной имитируемой работеэталону, так называемому оригиналу. Именно в этом и заключается назначение копий - имитировать оригинал. Кроме того, количество копий не ограничено - любое произведение может быть подвергнуто процессу многократного копирования.

Принимая данную информацию во внимание, теперь стоит задуматься над тем, чем же являются сделанные с одного негатива фотографии, отпечатанные с одной металлической формы гравюрные оттиски, выведенные из одного файла принтерные распечатки. Можно ли их назвать копиями? Нет, поскольку, строго говоря, они не имитируют какую-то одну единственную работу. Таким образом, основное отличие воспроизводимых видов искусства заключается в том, что их произведения не имеют оригиналов в принципе. Рассмотрим это утверждение на примере тех видов искусства, появление и развитие которых заставляло задуматься над вопросами, касающихся темы множественного производства творческих работ.

Как известно, у каждой пленочной фотографии есть негатив, существующий, как правило, в единственном экземпляре. Являются ли негативы оригиналами фотографий? Фотограф Бретт Уестон подчеркнул важность этого вопроса тем, что на свое восьмидесятилетие сжег все свои негативы, заявив, что только он мог печатать свои фотографии именно так, как изначально было им задумано; после смерти он не хотел, чтобы кто-то другой печатал фото, пользуясь его негативами. Гравюрные оттиски получают 


\section{Философия и культура 11(71) • 2013}

путем печати с уникальной металлической формы, называемой «доска». Каждая доска создается художником-автором в индивидуальном порядке и существует в единственном экземпляре. Считаются ли доски в таком случае гравюрными оригиналами? Цифровые файлы изображений являются носителями информации, без которой принтерная печать этих изображений невозможна. Уместно ли тогда говорить о файлах как об оригиналах произведений цифрового искусства? Эти вопросы спорны настолько же, насколько и вопрос о том, «что является истинным произведением кулинарного искусства рецепт или отдельно приготовленное блюдо» ${ }^{1}$.

На протяжение многих столетий проблема подлинности произведения предполагала рассмотрение аспектов его авторской уникальности. Поныне в тех случаях, когда мы четко можем провести различие между оригиналом и его копиями, мы обычно ценим оригинал за его единичность, как произведение, непосредственно созданное определенным человеком, как прямое, а не косвенное свидетельство вложенного таланта, сил и души художника. Однако большинство применяемых по отношению к традиционной живописи правил, по которым мы с уверенностью можем установить подлинность произведения, не всегда успешно применимы к современным формам искусства. Стремительное научно-техническое развитие оказывает влияние на все области человеческой деятельности. Сегодня в контексте воспроизводимого искусства представляется правомерным отказ от такого понятия как «оригинал», которое еще совсем недавно непременно ассоциировалось с результатами деятельности художника.

Проблема подлинности произведений современного искусства привлекает внимание и русских ученых. Семен Ерохин подчеркнул ее актуальность в одной из своих научных статей ${ }^{2}$, обратив при этом внимание на взгляды успешного искусствоведа и ценителя современного искусства - Марата Гельмана. С. Ерохин подчеркивает уверенность М. Гельмана в том, что с развитием цифровых технологии оригиналы вообще исчезнут из нашей жизни, что приведет к установлению принципиально новых типов взаимоотношений зрителя и художника, общества и искусства в целом. Относительно авторства

\footnotetext{
${ }^{1}$ Mitchell W. J. The Reconfigured Eye: Visual Truth in the Postphotographic Era. Cambridge MA: The MIT Press, 1994. P. 50.

${ }^{2}$ Ерохин С. В. Проблема подлинности произведений цифрового изобразительного искусства // Вестник Тамбовского университета. Серия: Гуманитарные науки. Тамбов, 2008. Вып. 10 (66). С. 159-165.
}

Гельман пишет: «... авторство принадлежит идее, а не технике, будь последняя архаичной (кисточка, резец, карандаш) или современной (фотография или цифровая графика). Современное искусство эту ситуацию скорее проявило, нежели объявило» ${ }^{3}$. В своих рассуждениях Гельман говорит о том, что «прерогатива оригинала давала на протяжении столетий почву для создания различных институций, его охраняющих и подтверждающих - это музеи, археологи, коллекционеры, продавцы, искусствоведыэксперты, на вооружении которых в наше время уже сотни научных способов атрибуции. Этого требует сегодняшний рынок искусства, за счет огромных средств которого и существуют все «надстройки», выдающие произведению сертификат «оригинала»» 4 .

Как ранее уже отмечалось, мы убеждены, что произведения воспроизводимых искусств не имеют оригинала. Впрочем, доказательство данного тезиса требует обстоятельного пересмотра устоявшихся принципов и подходов к определению понятий. Уточнения поднятых вопросов также представляется возможным лишь при условии, что мы позволим себе отойти от привычных дефиниций. На данном этапе ощущается необходимость во введении нового понятия, с помощью которого стало бы возможным переосмыслить и заново исследовать сложившееся проблемное поле.

В 2009 году канадский профессор философии Доминик Лопес опубликовал основательное научное исследование под названием «Философия компьютерного искусства» ${ }^{5}$ В нем Д. Лопес рассуждает о том, что интерактивность произведений компьютерного искусства обуславливает их множественную природу. Исследователь использует слово «display» в значении непостоянного, изменчивого объекта, порождаемого путем взаимодействия аудитории с отдельно взятым произведением искусства. Поскольку используемое Д. Лопесом английское слово «display» является чрезвычайно полисемичным, точный его перевод на русский язык представляет собой лингвистическую проблему. Кроме того, важно отметить, что в представленном Д. Лопесом контексте многократно употребляемое слово «display» обретает терминологических характер. В ходе нашего исследования мы попытались не только перевести

\footnotetext{
${ }^{3}$ Гельман М. О цифровом искусстве [Электронный ресурс] // Персональный сайт M. Гельмана. (URL: http://www.guelman. ru/artists/mg/original (дата обращения: 08.08.2013)).

${ }^{4}$ Там же.

${ }^{5}$ Lopes D. A Philosophy of Computer Art. London: Routledge, 2009.
} 
слово «display», но и решительно обособить его в отдельное философско-эстетическое понятие. В качестве русского эквивалента слова «display» мы предлагаем использовать словосочетание «эксплицитная версия». В рассматриваемом контексте «display» означает нечто выводимое, раскрытое, проявленное, представленное. Слово «эксплицитный» (от лат. explicitum - явный, открыто выраженный, внешний) отражает общий смысл понятия. Слово «версия» (от лат. versio - видоизменение, поворот), связанное напрямую с такими абстрактными понятиями, как вариативность, изменчивость, было выбрано нами с тем, чтобы подчеркнуть множественную сущность понятия.

Когда речь идет о воспроизводимых видах искусства, результатом творческой работы художника является произведение искусств, образованное множеством отдельно взятых эксплицитных версий. Такое произведение лишено уникального, существующего лишь в единственном экземпляре оригинала. Эксплицитные версии не подчинены какому-то эталону, они находятся наравне с другими относящимися к их множеству версиями. Логичным будет вывод о том, что эксплицитные версии всегда воспринимаются и оцениваются лишь совокупно. Аудитория, имея дело пусть даже с одной эксплицитной версией, сознает, что число всех возможных эксплицитных версий не ограничено. В защиту данной точки зрения выступает Д. Лопес, который подчеркивает, что любой «display» должен рассматриваться с позиции «один из многих». Обосновывая свою позицию, Д. Лопес проводит параллель между воспроизводимыми и исполнительскими искусствами и приводит пример концерта для двух или более солистов Арнольда Шёнберга «Фортепианный концерт», op. 42 (1942) (Concertante 1942 Piano Concerto). Исследователь убедительно доказывает, что мы можем оценить концерт только через оценивание бесконечного количества возможных его представлений, каждое из которых является эксплицитной версией.

Отдельные представления могут быть лучше или хуже, однако это не меняет музыкального произведения. При этом аудитория интуитивно дифференцирует имплицитные характеристики произведения от частных характеристик предлагаемого исполнения (акустика зала, профессионализм музыкантовисполнителей, слаженность оркестра, дирижерская интерпретация и т.п.). Художественно-эстетический потенциал музыкального произведения может быть реализован через различные его эксплицитные версии. Д. Лопес пишет: «Когда дело доходит до оценки, только представления (performances) имеют значение, а не само произведение. В конце концов, мы воспринимаем звучание музыки, которое предлагается нам только в виде исполнительской версии (performances). $\langle\ldots\rangle$ Конечно, существуют ноты, но они являются некой моделью для постановки представлений (performances)» ${ }^{1}$. Действительно, в ходе представления произведение раскрывается перед слушателем. Только после этого, слушатель может адекватно оценить и отдельное представление, и произведение в целом. Не ноты или что-нибудь еще, а их воспроизведение является единственной формой музыкального произведения, которая может быть адекватно воспринята и оценена.

Среди прочих исследователей, рассматривающих перекликающиеся с нашим исследованием вопросы, стоит выделить Нельсона Гудмана, который в 1968 году опубликовал книгу под названием «Языки искусства» ${ }^{2}$. Изложенная в книге теория направлена прежде всего на решение вопроса о подлинности множественных произведений, предполагая разделение искусств на два вида систем: аллографическая и автографическая. Музыкальное произведение, записанное нотами (условными знаками), является примером аллографической системы искусств, в то время как написанная картина, представляющая собой уникальное изображение, которое не может быть представлено при помощи системы символов и знаков, является примеров автографической системы. Аллографические искусства поддаются точной репродукции, потому что они могут быть записаны в виде последовательности условных обозначений (например, текст, ноты). Также Н. Гудман подчеркивает, что ноты или текст произведений могут быть скопированы, но при этом каждая копия имеет право называться подлинной. Таким образом, «аутентичность музыкального или литературного произведения не принадлежит какому-либо материальному объекту» ${ }^{3}$. Опираясь на идеи Н. Гудмана и следуя его логике, мы можем утверждать, что компьютерные произведения так же относятся к аллографическим системам, а их аутентичность также не ограничена материальными рамками.

Из числа современных продолжателей идей Н. Гудмана выделяется ученый Уильям Дж. Митчелл.

${ }^{1}$ Lopes D. A Philosophy of Computer Art. London: Routledge, 2009. C. 56.

${ }^{2}$ Goodman N. H. Languages of Art: An Approach to a Theory of Symbols. Indianapolis: Hackett Publishing, 1976.

${ }^{3}$ Там же. С. 51. 


\section{Философия и культура 11(71) • 2013}

В книге «Перенастроенный глаз» ${ }^{1}$ У. Дж. Митчелл развернуто изложил своё мнение о том, как следует рассматривать и оценивать компьютерное и цифровое искусство. Позиция и некоторые доводы У. Дж. Митчелла во многом схожи с уже упомянутыми взглядами Д. Лопеса. Однако, У. Дж. Митчелл выстроил свое обоснование несколько иначе, взяв за основу идею Нельсона Гудмана об «одноступенчатом» и «двухступенчатом» видах искусства. Эскиз и полароидный снимок являются примерами одноступенчатого искусства, а музыкальное произведение - двухступенчатого: первая ступень - процесс сочинения, результатом которого становятся нотный текст, вторая ступень - музыкальное исполнение. Цифровое изображение, отмечает У. Дж. Митчелл, также представляет собой пример двухступенчатого искусства: визуализация следует за первоначальным кодированием.

В целом мы согласны с мыслью У. Дж. Митчелла, считая, что цифровые и компьютерные произведения существуют в двух формах: в исходных и в производных. Результат первой ступени - работа в исходной форме (файл и т.п.), результат второй ступени - работа в производной форме (визуализация на мониторе, принтерная распечатка и т.п.). При этом именно результат второй ступени может быть воспринят и оценен зрителями. Очевидно, что ноты произведения должны быть переведены в форму музыкального исполнения, прежде чем слушатель сможет воспринимать и оценивать произведение. Аналогичным образом, произведения всех воспроизводимых видов искусства требуют «представления». Негативы фотографий, файлы графических редакторов и т.п., безусловно являясь обязательными и неотъемлемыми элементами творческого процесса, не предназначены для демонстрации и не могут быть в полной мере восприняты до тех пор, пока не будут воплощены и представлены в доступной зрителю форме. Проще говоря, прежде чем представить произведение на рассмотрение аудитории, необходимо облечь его в пригодную для целей перцепции форму. Теперь, размышляя над ранее предложенным вопросом о кулинарном искусстве, мы находим уместным указать на то, что оценить талант повара можно, лишь попробовав приготовленное им блюдо, а не прочитав его рецепт. Более того, и фотографии, и гравюры и другие произведения воспроизводимых искусств могут быть неоднократно воплощены самыми разными спосо-

${ }^{1}$ Mitchell W. J. The Reconfigured Eye: Visual Truth in the Postphotographic Era. Cambridge MA: The MIT Press, 1994. бами, сродни тому, как музыкальные произведения подвергаются различным интерпретациям.

Действительно, характеристики различных фотокарточек, сделанных с одного и того же негатива, могут варьироваться. Условия фотолаборатории и используемые материалы (фотореактивы, фотобумага и др.) не постоянны и переменчивы, но при этом, они непосредственно влияют на конечный результат работы фотографа. Логичным выводом будет заключение, что каждая фотография уникальна. Похожесть или непохожесть объектов не имеет значения. Сродни копиям произведений, в некоторых случаях разница между фотографиями не уловима невооруженным глазом, тогда как в других случаях разница очевидна с первого взгляда. Однако, фотографии, сделанные с одного негатива, нельзя назвать копиями, ведь каждая из них является результатом творческой работы фотографа-художника. Кроме того, фотографии не восходят к какому-то единому эталону. Негатив, не являясь конечной, экспонируемой формой произведения, не может быть визуально воспринят аудиторией.

В искусстве гравюры ситуация обстоит похожим образом. Как и производство досок, изготовление гравюрных оттисков с досок - это творческий процесс, в ходе которого художник может пробовать различные комбинации материалов и инструментов (бумага, красящий раствор и т.п.). Художник так же волен из раза в раз использовать одни и те же материалы, инструменты и принципы работы. Справедливо утверждать, что в первом случае получаемые оттиски будут обладать очевидно уникальными чертами. Во втором же случае закономерно ожидать, что оттиски будут похожи друг на друга как капли воды. Однако же, ни в первом, ни во втором случаи, оттиски не имеют и не могут иметь одного единственного эталонного оттиска, они так же не являются копиями доски. Несмотря на то, что оттиски, сделанные самим автором, по обыкновению стоят дороже, чем те, что были отпечатаны после смерти художника, любой оттиск является прямым следствием творческой работы художника. Что же касается досок, как и негативы фотографий, они не могут быть восприняты и оценены зрителями. Безусловно, доски могут представлять огромную историческую ценность и быть предметом всеобщего восхищения, однако художественную ценность в первую очередь представляет конечный результат работы - оттиск.

Сродни фотографиям и гравюрным оттискам, произведения цифрового и компьютерного искусства могут по-разному выглядеть в зависимости от самых разных обстоятельств, таких, например, 
как технические характеристики и физические параметры выводящего оборудования. В случае с компьютерными технологиями, размеры и пропорциональный формат мониторов, их разрешение и яркость могут меняться, что напрямую сказывается на выводимом изображении. Вместе с тем собственно файл цифрового произведения не может быть зрительно воспринят до тех пор, пока выводящее оборудование не будет задействовано.

Более того, когда речь идет о цифровых изображениях, полученных путем первоначального моделирования и последующей визуализации геометрических данных файла, результатом визуализации одного и того же исходного файла могут стать совершенно разные изображения, что объясняется возможными вариативными отклонениями, возникающими в процессе применения разных систем рендеринга. В качестве яркого примера можно привести историю про чайник, которая на сегодняшний день хорошо известна почти каждому, кто занимается трехмерной графикой. Чайник, о котором идет речь, был смоделирован в Университете Юты на заре трехмерной компьютерной графики. С тех пор копии этой модели были распространены по всему миру, оказавшись в самых разных лабораториях, занимающихся вопросами компьютерной графики. Множество различных систем рендеринга было применено к файлу, явив сотни вариантов визуализации: гладкие и шершавые, матовые и блестящие, металлические, деревянные, стеклянные и даже меховые чайники были получены на основе одного единственного файла.

Как мы видим, когда речь идет о воспроизводимых видах искусства, результатом работы творца становится произведение искусства, образованное множеством различных эксплицитных версий. При этом, эксплицитные версии не имитируют какой-то отдельно взятый эталон, они могут быть неразличимо похожими друг на друга, а могут существенно разниться. Однако, выше приведенный пример про чайник заставляет задуматься над несколько иным вопросом: как и насколько сильно должны разниться две работы, прежде чем их можно будет признать двумя отдельными произведениями? Этот вопрос приобретает особую актуальность в контексте современных компьютерных технологий, где возможность интерактивности привносит дополнительную проблематичность. Мы попытаемся ответить на этот вопрос в ходе анализа конкретных произведений современного искусства.

Теперь же, пробуя применить полученные теоретические выводы, перейдем к непосредственному рассмотрению произведений. Примеры позволят нам убедиться, что в реальности грань между копией, эксплицитной версией и собственно произведением зачастую стирается, в особенности, если речь заходит об интерактивном компьютерном искусстве. Рассмотрим пример компьютерного произведения. Джордж Льюис, американский композитор и тромбонист, широко известен своими музыкальными экспериментами и импровизациями. Начиная с восьмидесятых годов, он выступает в «дуете» с различными интерактивными компьютерными системами. Д. Льюис делится опытом в одной из своих научных статьей ${ }^{1}$, где он подробно описывает особенности программного обеспечения Voyager. «Работая с Voyager, импровизатор вступает в диалог с интерактивным «виртуальным импровизирующим оркестром». Компьютерная программа анализирует аспекты импровизационного выступления человека в режиме реального времени и, основываясь на анализе данного выступления, программа реагирует на поведение человека, генерируя как ответные, так и полностью независимые, диктуемые лишь внутренними процессами программы, реакции» ${ }^{2}$. Таким образом, результатом каждого живого выступления Д. Льюиса и Voyager становится неповторимое музыкальное произведение.

Д. Лопес рассматривает творческие эксперименты Д. Льюиса в качестве примера того, как интерактивное произведение компьютерного искусства (в данном случае Voyager) способно порождать другие произведения. Д. Лопес задается вопросом о том, «в каких случаях компьютер можно считать устройством для создания совершенно новых произведений, а в каких случаях компьютер синтезирует лишь различные эксплицитные версии одной и той же работы?» .

В случаe с Voyager и Д. Льюисом, компьютерная программа «слушает» и реагирует на человеческое поведение, генерируя не просто очередную эксплицитную версию, а ранее не существовавшее, абсолютно новое произведение. Теперь рассмотрим другой пример, когда результатом интеракции человека и компьютера становится эксплицитная версия. F2T - это интерактивный проект, интегрирующий такие разнохарактерные области, как скульптура,

\footnotetext{
${ }^{1}$ Lewis G. E. Too Many Notes: Computers, Complexity and Culture in Voyager // Leonardo Music Journal. 2000. Vol. 10. P. 33-39.

2 Там же. C. 33.

${ }^{3}$ Lopes D. A Philosophy of Computer Art. London: Routledge, 2009. P. 54.
} 


\section{Философия и культура 11(71) • 2013}

робототехника, хип-хоп и SMS. Создатель этого проекта - Тома Шарвериа (Thomas Charvériat), французский художник, куратор, исследователь различных аспектов интерактивности в искусстве. Главный элемент интерактивной инсталляции F2T - «Рэппер», центральная скульптура, которая, как можно догадаться, «читает» рэп. Исполняемые рэп-тексты генерируются на основе SMS-сообщений, присылаемых зрителями. Bce SMS-сообщения анализируются и проверяются на совпадение с какимилибо словами из более ста тридцати заложенных в программу хип-хоп фраз и выражений, написанных поэтом и композитором Джимом Барнардом (Jim Barnard). Программа «составляет» рэп-текст, собирая его из фиксированного набора фраз, каждая из которых была заранее озвучена реальным человеком, рэп-исполнителем. Таким образом, каждая отдельная экспозиция инсталляции имеет своим результатом новую хип-хоп композицию.

Однако же, допустимо ли считать каждую такую хип-хоп композицию самостоятельным произведением искусства? Чем же все-таки является результат интеракции аудитории с F2T: эксплицитной версией или произведением? Более того, возникают общие вопросы: существуют ли определенные правила, следуя которым, можно установить, когда результат взаимодействия с интерактивным компьютерным произведением является самостоятельной творческой работой, а когда лишь еще одной эксплицитной версией? Как следует дифференцировать произведения, их эксплицитные версии и копии? Что бы понять сущность компьютерного искусства и установить, что конкретно является произведением компьютерного искусства, необходимо ответить на данные вопросы.

Рассмотрев все выше перечисленные примеры произведений, мы приходим к выводу о том, что художник традиционных видов искусства сам взаимодействует с исходной формой своих произведений с целью экспликации их скрытого эстетического потенциала. Именно художник контролирует процесс получения производной формы, т.е. законченной эксплицитной версии произведения. Сталкиваясь с современными интерактивными технологиями, аудитория получает возможность взаимодействовать с произведением и самостоятельно генерировать эксплицитные версии, она как бы частично перенимает на себя роль художника. При этом художники осознано стремятся делегировать свои обязанности. Происходит это по разным причинам, например, желания художника обогатить эстетический опыт своей аудитории путем вовлечения их в общее артпространство.
Вернемся к инсталляции F2T. Очевидно, что по аналогии с рассмотренными примерами гравюр и фотографий, в случае с F2T мы имеем дело с эксплицитными версиями, а, следовательно, ни одна из получаемых хип-хоп композиций не может считаться самостоятельным произведением, каждая из них является лишь переменным вариантом одного единственного произведения F2T. F2T является наглядным примером произведения воспроизводимого искусства, образованного множеством хипхоп композиций. Аудитория зрителей-участников действительно взаимодействует с исходной формой произведения. В ходе активной интеракции зрители-участники «раскрывают» произведение, приводя его в производную форму, получая эксплицитную версию. Кроме того, как можно заметить, одним из ключевых слов в описании инсталляции F2Т является прилагательное «фиксированный», которое в данном контексте синонимично слову «ограниченный». Эти описательные прилагательные не имеет ничего общего с тем, что обычно подразумевают под творчеством. Зритель является пользователем, но не творцом. Несмотря на то, что аудитория взаимодействует с произведением искусства, она сам не создает ничего качественно нового, она лишь эмпирически осваивает компьютерную программу, действуя в рамках, которые заранее были предопределены автором, создателем F2T.

Теперь ранее упомянутый пример взаимодействия Д. Льюиса и программы Voyager начинает сбивать с толку. Рассмотрим еще один пример некомпьютерного искусства, который поможет нам доказать, что в некоторых случаях процесс взаимодействия с произведением искусств порождает новое самостоятельное произведение. В 2010 году американский писатель Джонатан Сафран Фоер (Jonathan Safran Foer) опубликовал книгу под названием «Дерево кодов», которая характеризуется гипертекстовостью. За основу произведения был взят рассказ «Улица крокодилов», впервые опубликованный Бруно Шульцем (Bruno Schulz) в 1934 году. Д. С. Фоер создал «Дерево кодов» путем «перебирания» оригинального текста: изъяв большую его часть, он оставил лишь отдельные слова, словосочетания и небольшие отрывки предложений, которые сложились в новое литературное произведение.

В данном случае мы снова видим, что произведение искусств выступает в роли средства, используемого для создания новой творческой работы. При этом независимость книги «Дерево кодов» очевидна - автор решительно отделил её от исходного рассказа. «Улица крокодилов» и «Дерево кодов» - это 
самостоятельные произведения, каждое из которых воспринимается и оценивается отдельно от другого. Однако между двумя этими произведениями существует прямая неразрывная связь, которой нельзя пренебречь. Если бы Д. С. Фоер взял за основу не рассказ Бруно Шульца, а любое иное литературное произведение, то в результате написал совершенно другую книгу, хотя бы и с названием «Дерево кодов». Подобным образом литературные произведения вдохновляют художников на создание иллюстраций. К примеру, между поэмой М. Ю. Лермонтова «Демон» и картиной М.А. Врубеля «Демон сидящий» также существует непосредственная связь. Тем не менее, картина М. А. Врубеля безусловно представляет собой самостоятельное произведение, которое может рассматриваться как и в контексте вдохновившей его поэмы, так и само по себе.

Как мы видим, произведения всегда в первую очередь рассматриваются отдельно от всех других произведений и являются уникальными во всех смыслах объектами. Однако же, когда речь заходит об эксплицитных версиях произведений, мы неизбежно рассматриваем их в некоторой абстрактной совокупности, даже несмотря на то, что они могут быть различными, даже в каком-то смысле уникальными. Увидев один эксплицитный вариант, мы получаем представления сразу обо всех других возможных, существующих или даже будущих эксплицитных вариантах данного произведения.

В заключение отметим, что трансформация мира искусства в эпоху технического воспроизведения - процесс, заслуживающий самого пристального внимания исследователей различных областей. Как мы выяснили, истинный художественно-эстетический потенциал произведений воспроизводимых искусств может быть реализован через их различные эксплицитные версии. Введенное понятие эксплицитных версий помогло нам расширить и уточнить понятийный аппарат исследуемой области. С точки зрения философско-эстетических исследований рассмотрение аспектов оригинальности, подлинности, уникальности, единичности и множественности произведения искусства представляется необходимым; все эти понятия должны быть дифференцированы и проанализированы в современном контексте компьютерного искусства. Разностороннее исследование вопросов, касающихся множественной природы компьютерных произведений, позволяет глубже проникнуть в сущность современного искусства и осознать тенденции его развития.

Освобожденное от подчинения ритуальной функции, сегодняшнее произведение искусства становится, из-за абсолютного преобладания его экспозиционной ценности, новым явлением, где художественная ценность и эстетическая выразительность выступают как наиболее важные характеристики. Именно они в первую очередь волнуют современного зрителя. Художественное произведение воспринимается как эстетический объект, а аспекты оригинальности или подлинности не оказывают прямого влияния на его способность вызывать восхищение окружающих. Уникальность идеи доминирует над материальной единственностью произведения: даже копии способны вызывать глубинные эстетические переживания у большинства людей. «Использование цифровых технологий в изобразительном искусстве наносит удар не по подлинности или оригинальности, а по характерной для европейской культурной традиции фетишизации произведений изобразительных искусства» ${ }^{1}$. Именно поэтому нет никакой нужды сопротивляться новым технологиям и обвинять их в девальвации изобразительного искусства. «Нужно не отрицать технику, а подчинить ее духу...» ${ }^{2}-$ писал Бердяев еще до появления большинства современных технологий, которые открылись компьютерному художнику. Но прежде чем «подчинить технику», ее необходимо всесторонне изучить.

В ходе нашего исследования мы убедились в том, что большинство интерактивных произведений искусства необходимо рассматривать в индивидуальном порядке. Попытки выработать общие принципы и универсальную методологию их исследования не привели к окончательным результатам. На данном этапе развития компьютерных технологий художники продолжают искать пределы возможностей своего нового творческого инструментария, и поэтому их творчество носит экспериментальный характер. По этой причине каждое отдельно взятое произведение требует частного подхода, т.к. только таким образом все его уникальные характеристики могут быть учтены. Вместе с тем обозначенное проблемное поле перекликается с целым рядом других важных для современной эстетики и искусствоведения вопросов подлинности и авторства произведений, популярности и массовости искусства. Мы полагаем, что полученные нами теоретические выводы послужат импульсом для дальнейших исследований в области компьютерного искусства.

${ }^{1}$ Ерохин С. В. Эстетика цифрового изобразительного искусства. СПб: Алетейя, 2010. С. 132.

2 Бердяев Н. А. Царство духа и царство Кесаря. Париж: YMCA press, 1951. C. 46. 


\section{Философия и культура 11(71) • 2013}

\section{Список литературь:}

1. Беньямин В. Произведение искусства в эпоху его технической воспроизводимости.

Избранные эссе. М.: Медиум, 1966.

2. Бердяев Н. А. Царство духа и царство Кесаря. Париж: YMCA press, 1951.

3. Галкин Д. В. Техно-художественные гибриды, или произведение искусства в эпоху его компьютерного производства (V.1.0) // Гуманитарная информатика. Томск, 2007. № 4. C. 22-38.

4. Гельман М. О цифровом искусстве [Электронный ресурс] // Персональный сайт М. Гельмана. (URL: http://www.guelman.ru/artists/mg/original).

5. Ерохин С. В. Проблема подлинности произведений цифрового изобразительного искусства // Вестник Тамбовского университета. Серия: Гуманитарные науки. Тамбов, 2008. Вып. 10 (66). С. 159-165.

6. Ерохин С. В. Эстетика цифрового изобразительного искусства. СПб: Алетейя, 2010.

7. Эстетика и теория искусства XX века. Хрестоматия. М.: ACADEMIA XXI: Прогресс-традиция, 2007.

8. Goodman N.H. Languages of Art: An Approach to a Theory of Symbols. Indianapolis: Hackett Publishing, 1976.

9. Lewis G. E. Too Many Notes: Computers, Complexity and Culture in Voyager // Leonardo Music Journal. 2000. Vol. 10. P. 33-39.

10. Lopes D. A Philosophy of Computer Art. London: Routledge, 2009.

11. Mitchell W. J. The Reconfigured Eye: Visual Truth in the Post-photographic Era. Cambridge MA: The MIT Press, 1994.

\section{References (transliteration):}

1. Ben'yamin V. Proizvedenie iskusstva v epokhu ego tekhnicheskoi vosproizvodimosti. Izbrannye esse. M.: Medium, 1966.

2. Berdyaev N. A. Tsarstvo dukha i tsarstvo Kesarya. Parizh: YMCA press, 1951.

3. Galkin D. V. Tekhno-khudozhestvennye gibridy, ili proizvedenie iskusstva v epokhu ego komp'yuternogo proizvodstva (V.1.0) // Gumanitarnaya informatika. Tomsk, 2007. № 4. S. 22-38.

4. Gel'man M. O tsifrovom iskusstve [Elektronnyi resurs] // Personal'nyi sait M. Gel'mana. (URL: http://www.guelman.ru/artists/mg/original).

5. Erokhin S. V. Problema podlinnosti proizvedenii tsifrovogo izobrazitel'nogo iskusstva. // Vestnik Tambovskogo universiteta. Seriya: Gumanitarnye nauki. Tambov, 2008. Vyp. 10 (66). S. 159-165.

6. Erokhin S. V. Estetika tsifrovogo izobrazitel'nogo iskusstva. SPb: Aleteiya, 2010.

7. Estetika i teoriya iskusstva XX veka. Khrestomatiya. M.: ACADEMIA XXI: Progress-traditsiya, 2007. 